\title{
Erratum to: Collaborative Care: a Pilot Study of a Child Psychiatry Outpatient Consultation Model for Primary Care Providers
}

\author{
Elise M. Fallucco, MD \\ Emma Robertson Blackmore, PhD \\ Carolina M. Bejarano, BS \\ Chelsea B. Kozikowski, BA \\ Steven Cuffe, MD \\ Robin Landy \\ Anne Glowinski, MD

\section{Erratum to: J Behav Health Serv Res \\ DOI: $10.1007 / \mathrm{s} 11414-016-9513-\mathrm{Z}$}

The last name of the fourth author is misspelled in the published article. "Kozikowksi" should be

"Kozikowski" as shown in this erratum.

Address correspondence to Elise M. Fallucco, MD, Division of Psychiatry, Nemours Children's Specialty Care, Jacksonville, FL, USA. Email: efallucc@ nemours.org.

Elise M. Fallucco, MD, Center for Health Care Delivery Science, Nemours Children's Specialty Care, Jacksonville, FL, USA. Email: efallucc@nemours.org

Carolina M. Bejarano, BS, Center for Health Care Delivery Science, Nemours Children's Specialty Care, Jacksonville, FL, USA.

Chelsea B. Kozikowski, BA, Center for Health Care Delivery Science, Nemours Children's Specialty Care, Jacksonville, FL, USA.

Robin Landy, Center for Health Care Delivery Science, Nemours Children's Specialty Care, Jacksonville, FL, USA.

Emma Robertson Blackmore, PhD, Department of Psychiatry, University of Florida - College of Medicine, Jacksonville, FL, USA.

Steven Cuffe, MD, Department of Psychiatry, University of Florida - College of Medicine, Jacksonville, FL, USA.

Robin Landy, Department of Psychiatry, University of Florida - College of Medicine, Jacksonville, FL, USA.

Anne Glowinski, MD, Department of Psychiatry (Child), Washington University, St. Louis, MO, USA.

The online version of the original article can be found at http://dx.doi.org/10.1007/s11414-016-9513-z.

Journal of Behavioral Health Services \& Research, 2016. 515. (C) 2016 National Council for Behavioral Health. DOI 10.1007/s11414-016-9518-7 